\title{
Chinese and Foreign Cooperation in Tertiary Education Management in Central regions of China Difficulties and Developments
}

\author{
Daoxun Wang \\ The International School \\ Huanghe Science and Technology College \\ Zhengzhou, China \\ e-mail:frankwdx@126.com
}

\begin{abstract}
Chinese and foreign cooperation in running tertiary education institutions in the central regions of China has the characteristics of short development time, limited expansion and little practical experience. It is highly subject to the constraints of the overall level of education, and therefore still in the initial period as a whole. The analysis of Chinese and foreign cooperation in managing tertiary institutions has just begun and there are some problems in the process of development. The present status of Chinese and foreign cooperation in education management in the central regions demonstrates that it is very important to break through the difficulties. The writer has identified three contradictions in the current process and believes that we need to analyse and find the factors which currently restrict Chinese and foreign cooperation in tertiary institution management, and at the same time, establish an effective system for Chinese and foreign cooperation.
\end{abstract} System

Keywords-Cooperative Education; Difficulties; Development

\section{INTRODUCTION}

Chinese and foreign cooperation in running tertiary institutions (universities and colleges) has made a contribution in the aspects of developmental models, educational philosophy, curriculum construction, professional settings, teaching methods, and student management resulting in a strengthening of reform and adjustment to the structure for domestic colleges and universities. The advantages and characteristics of this cooperation have also become an increasingly important and indispensable part of higher education.

To accelerate the overall level of higher education, promote the cooperation between famous universities at home and abroad in building scientific bases and advance the development of education in the central regions is an important goal written into the Economic Zone construction planning for the Central Regions. Additionally, the responsibility for the development of high-quality human resources systems is placed on institutions with these cooperative projects. Only by strengthening research, analysing the experience, standardizing the school, introducing high and quality educational resources, digesting and absorbing advanced educational concepts, modernizing the educational model and improving the quality of education and teaching, can we promote cooperative management projects effectively.

\section{THREE CONTRADICTIONS IN CHINESE AND FOREIGN COOPERATION IN RUNNING SCHOOLS IN CENTRAL REGIONS}

\section{A. The contradiction between the students' quality and educational objectives}

The original purpose of cooperative schools is enable students to access foreign course content without going abroad. However, there is a large gap between students in cooperative schools and other students. Additionally there are obvious contradictions between teaching requirements and students' levels. As a consequence, the cooperative schools in the central regions do not take full advantage of their opportunities but increase and sharpen the contradictions to a certain extent.

\section{B. The contradiction between introduction and digestion of excellent resources.}

With the increasing levels of cooperation between Chinese and foreign education institutions in central regions, the laws and regulations are gradually improving. However, a low percentage of excellent foreign educational resources are used, especially in the professional core curriculum. Further, progress is hindered by the low proportion of foreign teachers from educational institutions in China. Therefore, it is difficult to guarantee teaching quality. Provincial conditions and school conditions are the bases of the survival and development for Chinese and foreign education cooperation. To grow and vitalize the educational environment of the central regions, foreign educational resources must have a localized process after absorption and digestion.

\section{The contradiction between public welfare principle and the profit motivation}

Combined foreign and Chinese teaching programs are very expensive for students. Due to the lack of clarity in the policies and regulations, there are obvious contradictions between the principle of public welfare and profit motivation 
for educational institutions. Therefore, it is difficult for those schools to discount their economic benefits, which becomes a restriction and a major bottleneck for the development of higher education in the central regions.

\section{A PROPOSAL FOR CHINESE AND FOREIGN COOPERATION IN RUNNING SCHOOLS IN CENTRAL REGIONS}

In view of this situation, we put forward the following proposal:

\section{A. The establishment of a coordination office for Chinese and foreign cooperation in institution management in central regions}

The coordination office can ask the experts to research various situations and issues. Likewise, we need to establish provincial or university-level research institutes for Chinese and foreign cooperation in institution management, particularly analyzing the issue of students' levels and educational objectives, and undertake the relevant analytical case studies.

\section{B. Professional development models}

The establishment of a provincial foreign personnel agency is a good way to share educational resources and improve the proportion and quality of usage of foreign resources. There are five approaches to achieve this goal.

1. Formulate a systematic plan for attracting and retaining qualified educational resource personnel

First, there is a need to co-ordinate institutional teaching and academic development by adhering to the sustainable development of universities and colleges. Second, create a scientific and rational plan for the attraction and retention of professionals by strengthening the investigations and research. Third, improve the management of the personnel by clarifying the academic standards and teaching ability requirements. Last, promote the balanced development of human resources and growth incentives, create an conducive environment for professional development, formulate a long-term method for personnel attraction and use a personnel evaluation system.

2. Employ more first-rate teachers and bolster the development and management of teachers

Foreign teachers are precious resources. By inviting outstanding foreign teachers to our country we can ensure the quality of coordination of programs.

3. Analyse and adopt a more internationalized course construction system.

The core of success of Chinese and foreign cooperation for tertiary education management lies in adopting badly needed internationalized courses and teaching materials. The reformation of courses should focus on the following three aspects. First, courses about our constitution, civic virtues, customs and history should be improved. Second, advanced international teaching materials should be imported and outstanding scholars should also be invited to the institutions to give lectures, etc. Third, the latest academic methods and research directions should be incorporated into the teaching process over time.

\section{FOCUS ON THE DISCIPLINE PEDAGOGY AND INCREASE} EFFORTS TO IMPROVE THE TEACHING CONTENTS AND METHODS

Schools should build up their own specialised courses. The new courses should be quickly effective and based on educational regulations to realize sustainable development. The teaching contents and methods should be assimilated to improve efficiency. An advanced educational system is also compulsory.

\section{ESTABLISH AN APPROPRIATE QUALIFICATION AND QUALITY CERTIFICATION SYSTEM}

Quality is the foundation for effective tertiary institution management and therefore certification is necessary and compulsory. Cross-country or international certification is very complex, but develop high-quality personnel, a system focusing on quality needs to be employed. This can be created by comparing educational management methods of different countries, and adopting best practice from each country. The qualification and quality certification system should involve the regulations for running institutions, evaluation of teaching quality and development of excellence in management in order to be accepted in international education circles.

\section{A. Learning from internal experience}

To increase the exchanges and cooperation with the universities in developed regions of China, the central regions need to try to create a students exchange system interprovincially, to inspire the outstanding students to study in other universities. A system of cross accreditation and recognition of credits and qualifications within the province should be developed to enable students to move between universities. . Through these different collaborative programs we can share resources and drive the development of cooperation in institution management within the central regions. In order to achieve it, the universities must set up the special funds on cooperation in Institution Management, which would be used for staff exchange and training, ensuring that $60 \%$ of the teaching staff are given exchange opportunities.

\section{B. A new method for cooperation in tertiary institution mangement}

First, the universities and colleges need to transform the internal management and stimulate cooperation in management systems.

Second, they need to improve the school board system, obey the laws and regulations to maintain the educational sovereignty and guarantee the legitimate rights of teachers and students. This includes three aspects: 1. Strengthen students' ability in international communication; 2. Improve their creative competence. In this process, practical experience teaching cannot be neglected. With internships and work exchange programs can adapt to the practical needs of labour 
market and competition more quickly; 3. Create programs to encourage students' psychological development.

Third, university boards to create a guiding ideology, adhering to the principles of public welfare, and consciously resist making the institution profit oriented. Furthermore, the government needs to have a strong leadership role in demanding improvements in the administrative and approval procedures, which can provide an open environment for the institutions running cooperative educational projects.

Also, the universities and colleges should create new methods of student management. Students should be allowed to enter schools more easily than to graduate. Teachers are required to contact parents to exchange information about the students if required. For universities with English-speaking cooperative programs, it is vital to develop a strong English environment.

\section{IMPORTANT ISSUES FOR CHINESE AND FOREIGN COORPERATION IN TERTIARY INSTITUTION MANAGEMENT IN THE CENTRAL REGIONS}

\section{A. Relationship between cooperative education and general education}

On one hand, the Chinese and foreign cooperation in institution management plays an important role in the process of promoting higher education reform and development in the central regions. First, it enriches the educational supply and meets the diverse educational needs of the people. Second, it transforms the educational mechanism and promotes educational reform. Third, it expands the financing channels and improves the school conditions; finally, it broadens the professional training opportunities and provides a large skilled workforce.

On the other hand, in order to maintaining the educational sovereignty of China, we need to prevent 'educational dumping' from developed countries. To achieve these goals, we need develop indigenous professionals capable of supporting China's development, and who can manage and improve the educational system and methods, and be innovative in developing students. Furthermore, we need to strengthen the research into the disadvantages and situations that operate against the development of higher education in the central regions in the process of cooperative education.

\section{B. Relationship between independent institutions and experimental assessment}

There are two objectives for Chinese and foreign cooperation in experimental management assessment: First, achieve sound development of cooperative education. Through strengthening the awareness of the reform and opening up in China, it will drive reform, develop an open mind and encourage positive action to promote the healthy and standard development of the Chinese and foreign cooperation in education. Second, to increase the effectiveness of the institution. We need to guarantee the validity of assessment as well as the reduction of formalism, maximising resource usage and saving, and achieving results. Therefore, the college cooperative education body effectively analyse experimental assessment and improve assessment methodology in order to promote the teaching quality.

\section{CONCLUSION}

Under the impact of economic globalization, multinational higher education has received a widespread interest. The Chinese-foreign cooperation in tertiary institution management is one of the main initiatives of multinational higher education developed after China's entry into the WTO. However, during the process of development, contradictions occurred. These contradictions in the central regions are particularly prominent. If the central regions want to constantly improve cooperation, it is not only necessary to understand the unique concepts of sound quality management and evaluation systems, but also to ensure the effective absorption of foreign educational resources. Only in this way, can Chinese and foreign education cooperation programs demonstrate strong vitality in the central regions. The gradual development of the elements of cooperation, enhancing competitiveness and promoting professional training models and educational reform support the development of the central regions..

\section{REFERENCES}

[1] Tan Zhen. The Impact of the Chinese and Foreign Cooperation in Running Schools on Higher Education of Henan Province [J]. Explore the decision-making, 2008 (9).)

[2] Xing Liping.The Research on Current status and Reform Strategies of Chinese and Foreign Cooperation in Running Schools of Henan Province [J]. Henan Education (College Edition), 2007 (2)..

[3] Li Kai. The Initial Exploration of Chinese and foreign Cooperation in Running Schools [J], Harbin Institute of Technology 2006.7.

[4] Qian Jingwei. The Analysis of Chinese and Foreign Cooperation in Running Schools [J]. Southwest University for Nationalities (Humanities and Social Science Edition), 2005 (3).

[5] Zhang Letian. The Chinese and Foreign Cooperation in running schools and the Introduction of foreign Excellent educational resources. Shanghai Education, 2005. 